\title{
Groundwater Modelling Software - Capabilities and Limitations
}

\author{
C. P. Kumar \\ Scientist 'F', National Institute of Hydrology, Roorkee - 247667 (Uttarakhand)
}

\section{Introduction}

Ground-water modeling has become an important methodology in support of the planning and decision-making processes involved in ground-water management. Ground-water models provide an analytical framework for obtaining an understanding of the mechanisms and controls of ground-water systems and the processes that influence their quality, especially those caused by human intervention in such systems. Increasingly, models are an integral part of water resources assessment, protection and restoration studies, and provide essential and cost-effective support for planning and screening of alternative policies, regulations, and engineering designs affecting ground water.

There are many different ground-water modeling codes available, each with their own capabilities, operational characteristics, and limitations. If modeling is considered for a project, it is important to determine if a particular code is appropriate for that project, or if a code exists that can perform the simulations required in the project.

In practice, it is often difficult to determine the capabilities, operational characteristics, and limitations of a particular ground-water modeling code from the documentation, or even impossible without actual running the code for situations relevant to the project for which a code is to be selected due to incompleteness, poor organization, or incorrectness of a code documentation. Systematic and comprehensive description of a code features based on an informative classification provides the necessary basis for efficient selection of a groundwater modeling code for a particular project or for the determination that no such code exists.

\section{Model Development}

A groundwater model application can be considered to be two distinct processes. The first process is model development resulting in a software product, and the second process is application of that product for a specific purpose. Groundwater models are most efficiently developed in a logical sequence.

\section{Model Objectives}

Model objectives should be defined which explain the purpose of using a groundwater model. The modelling objectives will profoundly impact the modelling effort required.

\section{Hydrogeological Characterization}

Proper characterization of the hydrogeological conditions at a site is necessary in order to understand the importance of relevant flow or solute transport processes. Without proper site characterization, it is not possible to select an appropriate model or develop a reliably calibrated model.

\section{Model Conceptualization}

Model conceptualization is the process in which data describing field conditions are assembled in a systematic way to describe groundwater flow and contaminant transport processes at a site. The model conceptualization aids in determining the modelling approach and which model software to use.

\section{Modelling Software Selection}

After hydrogeological characterization of the site has been completed and the conceptual model developed, a computer model software is selected. The selected model should be capable of simulating conditions encountered at a site. For example, analytical models can be used where field data show that groundwater flow or transport processes are relatively simple. Similarly, one-dimensional/ two-dimensional/ three-dimensional groundwater flow and transport models should be selected based upon the hydrogeological characterization and model conceptualization.

\section{Model Design (Input Parameters) \\ Model design includes all parameters that are used to develop a calibrated model. The input parameters include model grid size and spacing, layer elevations, boundary conditions, hydraulic conductivity/transmissivity, recharge, any additional model input, transient or steady state modelling, dispersion coefficients, degradation rate coefficients etc.}




\section{Model Calibration}

Model calibration consists of changing values of model input parameters in an attempt to match field conditions within some acceptable criteria. Model calibration requires that field conditions at a site be properly characterized. Lack of proper site characterization may result in a model calibrated to a set of conditions that are not representative of actual field conditions.

\section{Sensitivity Analysis}

A sensitivity analysis is the process of varying model input parameters over a reasonable range (range of uncertainty in value of model parameter) and observing the relative change in model response. Typically, the observed change in hydraulic head, flow rate or contaminant transport are noted. Data for which the model is relatively sensitive would require future characterization, as opposed to data for which the model is relatively insensitive.

\section{Model Verification}

A calibrated model uses selected values of hydrogeologic parameters, sources and sinks and boundary conditions to match historical field conditions. The process of model verification may result in further calibration or refinement of the model. After the model has successfully reproduced measured changes in field conditions, it is ready for predictive simulations.

\section{Predictive Simulations}

A model may be used to predict some future groundwater flow or contaminant transport condition. The model may also be used to evaluate different remediation alternatives. However, errors and uncertainties in a groundwater flow analysis and solute transport analysis make any model prediction no better than an approximation. For this reason, all model predictions should be expressed as a range of possible outcomes that reflect the assumptions involved and uncertainty in model input data and parameter values.

\section{Performance Monitoring Plan}

Groundwater models are used to predict the migration pathway and concentrations of contaminants in groundwater. Errors in the predictive model, even though small, can result in gross errors in solutions projected forwarded in time. Performance monitoring is required to compare future field conditions with model predictions.

\section{ASTM Guides}

Standard Guide for Describing the Functionality of a Ground-Water Modeling Code (ASTM D6033 - 96, 2002)

This guide is intended to encourage correctness, consistency, and completeness in the description of the functions, capabilities, and limitations of an existing ground-water modeling code through the formulation of a code classification system and the presentation of code description guidelines.

This guide presents a systematic approach to the classification and description of computer codes used in ground-water modeling. Due to the complex nature of fluid flow and biotic and chemical transport in the subsurface, many different types of ground-water modeling codes exist, each having specific capabilities and limitations. Determining the most appropriate code for a particular application requires a thorough analysis of the problem at hand and the required and available resources, as well as a detailed description of the functionality of potentially applicable codes.

Typically, ground-water modeling codes are non-parameterized mathematical descriptions of the causal relationships among selected components of the aqueous subsurface and the chemical and biological processes taking place in these systems. Many of these codes focus on the presence and movement of water, dissolved chemical species and biota, either under fully or partially saturated conditions, or a combination of these conditions. Other codes handle the joint movement of water and other fluids, either as a gas or a non-aqueous phase liquid, or both, and the complex phase transfers that might take place between them. Some codes handle interactions between the aqueous subsurface (for example, a ground-water system) and other components of the hydrologic system or with non-aqueous components of the environment.

The classification protocol is based on an analysis of the major function groups present in ground-water modeling codes. Additional code functions and features may be identified in determining the functionality of a code. A complete description of a code's functionality contains the details necessary to understand the capabilities and potential use of a ground-water modeling code. Tables are provided with explanations and examples of functions and function groups for selected types of codes. Consistent use of the descriptions provided in the classification protocol and elaborate functionality analysis form the basis for efficient code selection. 
Although ground-water modeling codes exist for simulation of many different ground-water systems, one may encounter situations in which no existing code is applicable. In those cases, the systematic description of modeling needs may be based on the methodology presented in this guide. This guide is one of a series of guides on ground-water modeling codes and their applications, such as Guides D 5447, D 5490, D 5609, D 5610, D 5611, and D 5718.

Complete adherence to this guide may not be feasible. For example, research developments may result in new types of codes not yet described in this guide. In any case, code documentation should contain a section containing a complete description of a code's functions, features, and capabilities.

This guide offers an organized collection of information or a series of options and does not recommend a specific course of action. This document cannot replace education or experience and should be used in conjunction with professional judgment. Not all aspects of this guide may be applicable in all circumstances. This ASTM standard is not intended to represent or replace the standard of care by which the adequacy of a given professional service must be judged, nor should this document be applied without consideration of a project's many unique aspects. The word "Standard" in the title of this document means only that the document has been approved through the ASTM consensus process.

Other ASTM Guides

D5447 Guide for Application of a Ground-Water Flow Model to a Site-Specific Problem

D5490 Guide for Comparing Ground-Water Flow Model Simulations to Site-Specific Information

D5609 Guide for Defining Boundary Conditions in Ground-Water Flow Modeling

D5610 Guide for Defining Initial Conditions in Ground-Water Flow Modeling

D5611 Guide for Conducting a Sensitivity Analysis for a Ground-Water Flow Model Application

D5718 Guide for Documenting a Ground-Water Flow Model Application

D653 Terminology Relating to Soil, Rock, and Contained Fluids

\section{Selection of Groundwater Modelling Software}

The model code should be selected provisionally at the end of the scoping study and definitely by the end of the conceptual modelling. Two fundamental areas need to be considered in selecting a model code; is it appropriate?, is it useable?

\section{Is it appropriate?}

During the scoping study the current ideas about how the aquifer is behaving will be gathered and throughout the conceptual modelling these hypotheses will be challenged and developed. We need to consider the modelling objectives (the questions which the model is being asked to address) and the key flow mechanisms identified during conceptual modelling and ask:

1. Can the code represent the key flow mechanisms? For example, a two dimensional single layer model will be inappropriate if vertical groundwater head gradients are known to be significant.

2. What simplifications are required to represent these key mechanisms?

3. Has the code been tested for similar problems to ours?

4. Can the code perform the kind of predictive runs that the modelling objectives will require?

5. Can the model be readily updated as our conceptual understanding grows?

\section{Is it useable?}

Since a regional groundwater model represents a significant capital investment and is likely to be used and updated for many years, it will probably be used by several in-house staff in addition to the people who develop it. Therefore, we should also ask:

1. How much effort is required to become familiar with the code?

2. Do we have access to the source code so that the way in which the calculations are performed can be investigated?

3. How good is the user manual? (Does it adequately explain how the code works? Are the input instructions correct? Are there examples data sets?)

4. How good is the user support (speed of response and technical content)?

5. Is there a good and well-tested user interface?

6. How good is the quality control of the code and its user interface?

7. Does the user interface allow digital data to be imported or exported in variety of common formats? 
Graphical user interface (GUI) selection

A number of the codes have a graphical user interface (GUI) which aids in the creation of input files for the model code to read and for visualizing the model output. The AQUA, ICMM and MIKE-SHE codes are supplied with their own proprietary GUIs while for MODFLOW there are a number of different interfaces available, including Processing MODFLOW, Visual MODFLOW and Groundwater Vistas (GV).

Experience shows that although user interfaces are helpful in creating the input files containing the spatial distributions of aquifer geometry and hydraulic parameters, they have limitations, which must be borne in mind. These include a lack of flexibility in creating time variant data (e.g. recharge and abstractions) for which spreadsheets or utilities written in FORTRAN or Visual Basic are often more powerful. In addition, it is not uncommon for a model code to be able to perform functions which the interface does not support.

Finally, the rapid development of these user interfaces has too frequently been at the expense of rigorous quality control. Consequently, the necessity for a model user to be familiar with and constantly check the ASCII data input and output files remains as important as ever.

MODFLOW GUIs are generally supplied with a compiled (executable) version of MODFLOW-96 which may contain minor enhancements (e.g. MODFLOWwin32 with Groundwater Vistas GUI)

The modular finite-difference groundwater flow model (MODFLOW) was developed by the U.S. Geological Survey (USGS) and first released in 1988 (McDonald \& Harbaugh, 1988). It has evolved continually and is now the most widely used program in the world for representing groundwater flow. It reads ASCII files containing the input data (recharge, abstraction, aquifer parameters, boundary conditions etc.) and performs calculations in order to output heads and flows.

MODFLOW's success as a modelling tool owes much to its original design. It was written in the early 1980 s as a modular code to replace the 500 or so pieces of groundwater modelling software which were scattered over the USGS's mainframes. It had to be accurate, easy to understand, easy to enhance and modify and computationally efficient. MODFLOW is well documented, logically programmed but has never pretended to do everything. As people have wanted to simulate processes of which MODFLOW was incapable, they have written their own modifications. MODFLOW is continuously under development. Details of the latest version can be downloaded from http://water.usgs.gov/nrp/gwsoftware/modflow.html.

A number of proprietary enhancements of the basic public domain MODFLOW code are available. These codes have been written to make significant changes to the original public domain code. In contrast to the public domain versions, the source code for these proprietary codes is not publicly available.

\section{Classification of Groundwater Software}

Frequently used groundwater software in various categories have been listed below. Some of the software belong to more than one category. Considering the large variability and the quick development of groundwater models, a new, more sophisticated model can often replace a previously applied model. Additionally, the reconsideration of the conceptual model and the regeneration of the mesh may need a new allocation of the parameters. Therefore, it is important that model data (information) are stored independently from a given model, with a preference for GIS-based databases. Considerable development in the field of userfriendly GIS and data base servers makes the set-up and the modification of models easier and more timeeffective. One such model is FEFLOW which incorporates mathematical modelling with GIS-based data exchange interfaces.

The input data for a groundwater model include natural and artificial stress, and parameters, dimensions, and physico-chemical properties of all aquifers considered in the model. A finer level of detail of the numerical approximation (solution) greatly increases the data requirements. Input data for aquifers are common values such as transmissivities, aquitard resistances, abstraction rates, groundwater recharges, surface water levels etc. The most common output data are groundwater levels, fluxes, velocities and changes in these parameters due to stress put into the model.

\section{Aquifer and Pump Testing}

Aquiferwin32 - Pumping test analysis, slug test analysis and step test analysis plus analytical groundwater flow modeling and pumping test simulations

AquiferTest Pro - Provides graphical analysis and reporting of pumping test and slug data for Confined Aquifers, Unconfined Aquifers, Leaky Aquifers, and Fractured Rock Aquifers

Infinite Extent - Pump test analysis software

\section{Groundwater Databases}


ChemGraph - ChemGraph provides a very efficient system for entering, storing, and reporting environmental and groundwater monitoring data.

Enviro-Base Pro - EnviroBase Pro is a user-customizable database of soil and chemical properties, drinking water standards, adsorption, dispersivity, and chemical half-life information.

EQuIS Geology/EQuIS Chemistry - EQuIS Geology/EQuIS Chemistry provide advanced database management system for environmental geology and chemistry data.

HydroGeo Analyst - HydroGeo Analyst is the complete solution for groundwater and borehole data management and visualization technology.

\section{Geochemical Software}

AquaChem - AquaChem is a powerful aqueous geochemistry package for graphical and numerical analysis and modeling of water quality data, featuring fully customizable database of physical and chemical parameters.

Hydrogeochem - Hydrogeochem is a coupled model of hydrologic transport and geochemical reaction in saturated-unsaturated media.

MINETQA2 for Windows is a Windows version of the popular EPA geochemical equilibrium speciation model capable of computing equilibria among the dissolved, adsorbed, solid, and gas phases

\section{Public Domain Software}

$B A L A N C E$ - BALANCE is a USGS computer program for calculating mass transfer for geochemical reactions in ground water.

GEOPACK - A comprehensive U.S. EPA geostatistical software system for conducting analysis of the spatial variability of one or more random functions.

HST3D - A Computer Code for Simulation of Heat and Solute Transport in Three-Dimensional Ground-Water Flow Systems

$M O C$ - MOC simulates $2 \mathrm{D}$ solute transport in flowing ground water

MOCDENSE - MOCDENSE is a variable density ground-water flow and solute-transport model. This version of MOCDENSE simulates the flow in a cross-sectional plane rather than in an areal plane.

MODFLOW - USGS Modular Three-Dimensional Ground-Water Flow Model

PEST - non-linear parameter estimation software for any numerical model.

PESTAN - Pesticide Transport is a U.S. EPA program for evaluating the transport of organic solutes through the vadose zone to ground water.

PHREEQE - PHREEQE is a USGS computer program designed to model geochemical reactions.

PLOTCHEM - A Water-quality data plotting software package

RECESS - RECESS is a group of six computer programs (RECESS, RORA, PART, TRANS, CURV and STREAM) for describing the Recession of Ground-Water Discharge and for Estimating Mean Groundwater Recharge and Discharge from Streamflow Records.

RETC - Retention Curve Program for Unsaturated Soils

$V L E A C H$ - VLEACH, a One-Dimensional Finite-Difference Vadose Zone Leaching Model, is a U.S. EPA program which describes the movement of an organic contaminant within and between three phases: (1) as a solute dissolved in water, (2) as a gas in the vapor phase, and (3) as an adsorbed compound in the solid phase. VS2DT - VS2DT is a USGS program for flow and solute transport in variably-saturated, single-phase flow in porous media. A finite-difference approximation is used in VS2DT to solve the advection-dispersion equation.

\section{USGS Ground Water Software}

AQTESTSS (Win) Version 1.2, 2004/07/02

Several spreadsheets for the analysis of aquifer-test and slug-test data

DDestimate (Win) Version 1.1

A spreadsheet application for simulating time series and estimating drawdowns.

GSFLOW (Linux/Win) Version 1.0.00, 2008/03/05

Coupled Ground-water and Surface-water FLOW model based on the USGS Precipitation-Runoff Modeling System (PRMS) and Modular Ground-Water Flow Model (MODFLOW-2005)

GW_Chart Version 1.18.0.0, 2008/07/07

Graphing application for MODFLOW, MOC3D, MODFLOW2000-GWT, ZONEBUDGET, SUTRA, MT3D, HST3D, UCODE-2005 and OPR-PPR. Also draws Piper diagrams.

HST3D (Unix/Linux/Win) Version 2.2.13, 2006/05/26

Three-dimensional flow, heat, and solute transport model

HYDROTHERM (Linux/Win) Version 3.1.0, 2008/03/01

Three-dimensional finite-difference model to simulate multiphase ground-water flow and heat transport in the temperature range of 0 to 1,200 degrees Celsius 
INFIL3.0 (Win) Version 1.0, 2008/06/19

A grid-based, distributed-parameter watershed model to estimate net infiltration below the root zone

MODFLOW-2000 with capability for ground-water management using optimization

$M F 2 K$-VSF (Win) Version 1.01, 2006/07/05

Three-Dimentional finite-difference ground-water model (MODFLOW)--2000 version--with variably saturated flow

MOC3D (DOS/DG/Mac/SGI/Sun) Version 3.52, 2004/01

3D method-of-characteristics ground-water flow and transport model integrated with MODFLOW-96

Model Viewer (Win) Version 1.2, 2008/06/25

Model Viewer is a computer program that displays the results of three-dimensional ground-water models

MODFLOW, MODFLOW-2005 AND RELATED PROGRAMS

Three-dimensional finite-difference ground-water mode

MODOPTIM (Win) Version 1.0, 2005/05/05

A General Optimization Program for Ground-Water Flow Model Calibration and Ground-Water Management in MODFLOW

PHAST (Linux/Win) Version 1.4.2-2411, 2007/11/17

PHAST is a 3-dimensional model for simulating ground-water flow, solute transport, and multicomponent geochemical reactions

PULSE

Model-Estimated Ground-Water Recharge and Hydrograph of Ground-Water Discharge to a Stream

SEAWAT Version 4.0, 2008/03/28

A computer program for simulation of three-dimensional variable-density ground water flow

SHARP (DOS/DG/SGI/Sun) Version 1.1, 09/03/2004

A quasi-three-dimensional, numerical finite-difference model to simulate freshwater and saltwater flow separated by a sharp interface in layered coastal aquifer systems

SUTRA and related programs

2D, 3D, variable-density, variably-saturated flow, solute or energy transport

Utility PIEs (Win) Version 1.7.11.0, 2008/04/02

Programs for simplifying the analysis of geographic information in U.S. Geological Survey ground-water models

VS2DT (Sun/Win) Version 3.2, 2004/10/18

Model for simulating water flow and solute transport in variably saturated porous media

WTAQ (DG/Win) Version 1.0, 2000/01/07

A computer program for calculating drawdowns and estimating hydraulic properties for confined and watertable aquifers

ZONEBDGT (DOS/DG/SGI/Sun) Version 1.0, 1996/12/20

Program for computing subregional water budgets for MODFLOW ground-water flow models

V. MODFLOW-based Software

GMS (Groundwater Modeling System) - GMS supports both finite-difference and finite-element groundwater models in 2D and 3D including MODFLOW 2000, MODPATH, MT3DMS/RT3D, SEAM3D, ART3D, UTCHEM, FEMWATER, PEST, UTEXAS, MODAEM and SEEP2D.

Groundwater Vistas - Complete groundwater model design and analysis for MODFLOW, MODFLOWSURFACT, MODPATH, MT3D and PEST. Now available with GW3D visualization and Remote Model Launch.

MODFLOW SURFACT - MODFLOW-based ground-water flow and contaminant transport model

MODPATH - A Particle Tracking Post-Processing Package for MODFLOW, the USGS 3-D Finite-Difference Ground-Water Flow Model

MODTECH - ModTech is a new 3D groundwater flow and mass transport software that enables you to model groundwater flow and contaminant transport within a real-world geographic (GIS) environment.

PMWIN (Processing MODFLOW for Windows) - PMWIN is a graphical interface for MODFLOW, MODPATH, PMPATH, MT3D, RT3D, MOC3D, PEST and UCODE

Visual MODFLOW - Visual MODFLOW Premium is the proven standard for professional 3D groundwater flow and contaminant transport modeling using MODFLOW-2000, MODPATH, MT3DMS and RT3D.

\section{Density-Dependent Flow}


FEFLOW - 2D/3D finite element subsurface flow system - model for density dependent groundwater flow, heat flow and contaminant transport

GMS (Groundwater Modeling System) - GMS supports both finite-difference and finite-element groundwater models in 2D and 3D including MODFLOW 2000, MODPATH, MT3DMS/RT3D, SEAM3D, ART3D, UTCHEM, FEMWATER, PEST, UTEXAS, MODAEM and SEEP2D.

$M O C D E N S E$ - It is a variable density ground-water flow and solute-transport model. This version of MOCDENSE simulates the flow in a cross-sectional plane rather than in an areal plane.

SEAWAT - A computer program for simulation of three-dimensional variable-density ground water flow

$S U T R A$ - It is a $2 \mathrm{D} / 3 \mathrm{D}$ ground water saturated-unsaturated transport model, a complete saltwater intrusion and energy transport model. SUTRA is integrated with Argus ONE for graphical pre and post processing.

\section{Unsaturated Flow \& Transport}

$B I O F \& T$ - BIOF\&T models biodegradation and bioremediation, flow and transport in the sat/unsat zones in 2 or 3 dimensions in heterogeneous, anisotropic porous media or fractured media

ChemFlux - ChemFlux is a contaminant transport software modeling package for modeling of mass transport, contaminant concentrations and plume migration.

FEFLOW - 2D/3D finite element subsurface flow system - model for density dependent groundwater flow, heat flow and contaminant transport

POLLUTE - Layered contaminant transport analysis from sources such as landfills, buried waste, spills, and disposal ponds.

SUTRA - SUTRA is a 2D/3D ground water saturated-unsaturated transport model, a complete saltwater intrusion and energy transport model. SUTRA is integrated with Argus ONE for graphical pre and post processing.

SVFlux 2D/3D - Finite element seepage analysis software. Perfomr 2D and 3D flow analysis in unsaturated or saturated soil.

Visual HELP for Windows - The most complete modeling environment for the HELP model for evaluating and optimizing landfill designs!

WHI UnSat Suite - A compilation of the most popular 1-D groundwater unsaturated zone models including VLEACH, VS2DT, PESTAN and HELP.

\section{Fracture Flow Software}

$B I O F \& T$ - BIOF\&T models biodegradation and bioremediation, flow and transport in the sat/unsat zones in 2 or 3 dimensions in heterogeneous, anisotropic porous media or fractured media

FEFLOW - 2D/3D finite element subsurface flow system - model for density dependent groundwater flow, heat flow and contaminant transport

FRAC3DVS - Three-dimensional, steady-state or transient, saturated or unsaturated flow in fractured or unfractured porous media.

SWIFT - Three-dimensional transient flow in fractured or unfractured, anisotropic, heterogeneous porous media. Viscosity dependency as a function of temperature and brine concentrations.

\section{Review of Selected Groundwater Software AQTESOLV}

AQTESOLV by HydroSOLVE Inc. is software designed to calculate hydraulic conductivity, storativity and other aquifer properties from data sets collected during slug and aquifer (pumping) tests.

AQTESOLV is user friendly. It can be mastered using the tutorial and help file. Most students pick up the software quickly. The Slug Test and Pumping Tests Wizards do a good job of walking the user through the input of data. A useful feature is the basic pictures on each input screen that show what each variable represents.

AQTESOLV can import text files generated by commonly used pressure transducers. Also, data can be manually entered or pasted from a spreadsheet. It is easy to change the input values once you have entered them, and to switch between English and SI units. After importing, the raw data can be manipulated using mathematical functions. For example, hydraulic head data can be converted to drawdown data.

Once the data are entered, the software offers a variety of solutions. This is where user-knowledge is important. AQTESOLV gives little guidance on selecting the appropriate solution for the data and hydrogeologic setting and the user is referred to the relevant literature for details on each solution. The user must also know how to correctly display the data (e.g. on linear or log scales), and how to transform the raw 
data into the form used by each solution. The software provides an automated matching feature, but the automated match is usually poor, and manual fitting of the solution lines to the data is recommended.

Incorporating output from AQTESOLV into a presentation or report is functional, but not fancy. A hard copy of the graphed data, your best fit line, and calculated parameters can be sent to a printer, or, exported as a Windows metafile. Overall, the software is easy to use, offers a variety of solutions, creates presentation-quality output, and saves time when compared to performing the analysis by hand.

AQTESOLV can be downloaded at (http://www.aqtesolv.com/). Depending on choices such as single-user or site license, standard or professional version, and commercial or academic application, prices vary from $\$ 500$ 1500 .

\section{AQUACHEM}

AquaChem manages water quality data, allowing the user to plot data, perform common statistical analyses, model water chemistry with PHREEQC, and create simple reports. AquaChem is compatible with Microsoft (MS) Office; the database created by AquaChem can be opened and modified in MS Access and data can be imported to AquaChem from text formatted and MS Excel files.

The most useful feature is the ability to plot data quickly. Map plots, displaying water quality data in diagrams using $\mathrm{X}$ and $\mathrm{Y}$ coordinates for station location, can be created and AutoCAD or common graphics files can be used as base map. Also, chemistry of water from different wells, or groups of wells, can be compared in various diagrams such as ternary, Piper, and Stiff. Saturation indices can be calculated with a built-in basic version of PHREEQC and data files can be constructed in AquaChem for input to PHREEQC for more rigorous modeling.

Statistical tools include trend analysis (Mann-Kendall, linear), normality tests, and evaluation of correlation between parameters. Although, database management and report preparation may be as easily performed in Excel and Access, the statistical tools in AquaChem and the ease and speed of creating diagrams used in aquatic chemistry allows the user to quickly analyze and present data. AquaChem is not a substitute for more advanced geochemical modeling programs but is a useful tool for interpreting data and discovering trends in the data. AquaChem is available from IGWMC (http://typhoon.mines.edu/software/igwmcsoft/) for $\$ 945$ for a single license.

\section{GFLOW}

GFLOW is an analytic element code that belongs in the arsenal of commonly used groundwater modeling tools. It solves groundwater flow problems by superimposing analytic solutions under DupuitForchheimer assumptions. In its most simple dress the code facilitates rapid construction and solution of a steady-state single-layer groundwater model containing multiple recharge and transmissivity zones with complicated internal boundary conditions. However, one of its most innovative aspects is its ability to perform conjunctive surface water/groundwater modeling.

GFLOW uses stream networks to route baseflow so that available streamflow responds to stresses such as pumping, an option that is particularly useful in determining the effect of wells on the headwaters of streams. It has several ways of simulating the interaction of groundwater with lakes, including the ability to perform detailed water balances in the presence of through-flowing streams, a capacity not yet available in other analytic element codes or MODFLOW. Together these options make it particularly useful in modeling unconfined flow in terrains (e.g. glacial) with closely spaced surface-water bodies.

A second innovation of the code is to facilitate use of the "stepwise" modeling approach. Often DupuitForchheimer assumptions are more valid for regional flow problems than for site-specific problems where vertical head gradients are important. To allow the speed of analytic elements to be mated with the flexibility of finite-differences, GFLOW supports automatic conversion of part of its domain to a local MODFLOW model with flux or constant head boundary conditions around the inset grid. Once the conversion is made, the user can add more complexity to geometry and properties inside the MODFLOW model.

Another advanced feature of the code is particle tracking that takes advantage of mass balance considerations to simulate flow lines from the water table below a stream to a well. There are "tricks" that are needed to most effectively perform analytic element modeling; the ample HELP material introduces the user to the technique's special vocabulary (e.g., "linesinks") and also provides a general guide to modeling, which makes the code a first-rate teaching tool. The GUI, compatible with all versions of Windowsâ, is workmanlike with excellent visualization tools related to surface water and calibration. A lot of thought has gone into converting readily available maps such as USGS coverages into base maps. GFLOW is available for $\$ 450$ from: http://www.haitjema.com/.

GMS (Groundwater Modeling System) 
GMS (Groundwater Modeling System) is a comprehensive software package for developing computer simulations of groundwater problems (flow and contaminant transport). The Environmental Modeling Research Laboratory at Brigham Young University in Utah oversees the continued development of GMS, but GMS is distributed commercially through a variety of vendors.

GMS provides tools for site characterization, model development, post-processing, calibration, and visualization. It supports TINs, solids, borehole data, 2D and 3D geostatistics, and both finite element and finite difference models in 2D and 3D, including MODFLOW, MODPATH, MT3D, RT3D, FEMWATER, SEEP2D, ART3D, MODAEM, SEAM3D, and UTCHEM. Parameter estimation is supported through the processes included with MODFLOW, PEST, and UCODE.

GMS's design, allows the user to select "modules" in custom combinations. These modules are related to pre- and post-processing, model selection, and calibration routines. Discussion of all modules is beyond the scope of this review, but many commercial vendors have websites with detailed descriptions of each module and how they can be used. New users can select specific modules for a current project and add modules as needs expand or change. Use of GMS saves time by having a modeling "package" that is the same for a variety of programs. The initial learning curve is steep. However, GMS uses the same "conceptual model" approach (discussed below) for alternative modeling programs (e.g., MODFLOW and FEMWATER).

A "conceptual model" approach is built into the map/GIS module. Here, a user defines the model properties (i.e., boundary conditions, hydraulic conductivity values, 2D and 3D model domain, etc.) in a GIS interface that is independent of the simulation codes. With a click of a button, model properties are transferred from the GIS interface to the appropriate grid cells or mesh elements. The advantage of this approach is the ability to quickly change a conceptual model, transfer these conditions to a new simulation, and evaluate the results. In addition, GMS allows more advanced users to easily see and edit the grid by grid values, without going to the final text file (although a quick check of the text files is always a good idea). GMS 6.0 can be fully integrated with ArcGIS if the user also has an ArcGIS license, allowing for a seamless transfer in creating conceptual models and producing final figures of modeling results.

In summary, GMS is a useful all around groundwater modeling package that offers the advantages of modular purchases, multiple model support, linkages to ArcGIS, conceptual model development, and integrated inversion routines. As with many software programs, new releases of GMS should be used cautiously with the understanding that some of the latest features may require revision before the full range of capabilities are functional.

\section{HYDRUS}

The HYDRUS software package (including the much anticipated three-dimensional capability) is a major upgrade and extension of the HYDRUS-2D/MESHGEN-2D software package (originally developed and released by U.S. Salinity Laboratory, PC-Progress and the International Groundwater Modeling Center). HYDRUS is a Microsoft Windows based modeling environment for analysis of water flow, solute, and heat transport in variably saturated porous media.

For flow, the code solves the mixed form of the Richards' equation with many functions for simulating hydraulic conductivity versus water content (or pressure head) relationships, including hysteresis. It allows root water uptake with compensation; spatial root distribution functions; and includes new soil hydraulic property models. The new code allows for dynamic, system-dependent boundary conditions (e.g., switching between pressure heads, seepage face, zero flux or atmospheric boundary depending on the position of the water level).

For solute transport, the code solves the advection dispersion equation, but with many processes not usually include in unsaturated zone codes. For example, in addition to the typical linear partitioning between soil, water, and gas phases, the code also simulates the following processes: non-linear and non-equilibrium partitioning between phases; diffusion in the gas phase; zero- and first-order degradation kinetics; including decay chains (e.g., for nitrates and radionuclides); adjective flow in a dual-porosity system allowing for preferential flow in fractures or macropores while storing water and dissolved chemicals in the matrix; transport of viruses, colloids, and/or bacteria using an attachment/detachment model; filtration theory; and blocking functions; and flowing particles in two-dimensional applications. Hydrus also includes a new constructed wetland module (only in 2D).

HYDRUS still allows optimization in 1D and 2D. Unfortunately, optimization is not provided for 3D applications. Another useful new feature is better print management (printing at regular time intervals or after a constant number of time steps).

The GUI is much improved. It includes many new functions improving the user-friendliness, such as drag-and-drop, context sensitive pop-up menus after clicking on objects, selection and editing of multiple objects in the same dialog window, and allowing multiple projects and views to be opened at the same time in the HYDRUS main window. One of the best new features is that time-varying and cumulative fluxes can be calculated and displayed across internal meshlines. 
The only negatives associated with the program are that the User's Guide could be more complete. Not all features are explained well enough for a modeler without HYDRUS experience to easily follow. However, the on-line discussion forum is very helpful for those who take advantage of it. The forum can be found at http://www.pc-progress.cz/_Forum/default.asp

Pricing varies depending on the level purchased. Single-computer licenses are \$1500 for HYDRUS that can handle applications for simple (hexahedral) geometries, and $\$ 1800$ for HYDRUS standard for 3D geometries comprising of flexible 2-D geometries and layers for the third dimension. A professional version is expected in summer 2007, which will allow application of general, flexible 3D geometries. The original, publicdomain version of HYDRUS1D is included in the HYDRUS package and may still be downloaded for free from the IGWMC web site http://www.mines.edu/igwmc/software/igwmcsoft/ hydrus1d.htm. HYDRUS may be purchased by visiting http://typhoon.mines.edu/ software/igwmcsoft/hydrus3d.htm

\section{MIKESHE}

The MIKE SHE code is a powerful, physically-based, distributed parameter, fully integrated code for three-dimensional simulation of hydrologic systems. It has been successfully applied at multiple scales, using spatially distributed, continuous climate data to simulate a broad range of integrated hydrologic, hydraulic and transport problems in humid as well as more arid areas. For example, in the U.S., it has been used extensively in South Florida on Everglades Restoration projects, in Colorado, at Rocky Flats (a former DOE nuclear manufacturing facility) and in the Black Mesa basin of northeastern Arizona.

MIKE SHE was developed by DHI Water and Environment (http://www.dhi.dk/). It was originally developed as 'SHE' along with the British Institute of Hydrology and SOGREAH (France). In the 2003 version, all major hydrologic flow processes are dynamically coupled, including 2-D overland flow, 1-D channel flow, 3-D saturated zone flow, 1-D (Richard's based) unsaturated zone flow, snowmelt and evapotranspiration. Overland flow utilizes DEMs, while channel flow is simulated through the MIKE 11 code, which has extensive capabilities including, user-defined regulating structures, water quality and sediment transport, and a morphological module. It is also capable of simulating integrated advective-dispersive transport, sorption, biodegradation, geochemistry (including PHREEQC), and macropore flow, generally applicable for most hydrologic, water resources and contaminant transport applications. In contrast to similar codes, MIKE SHE utilizes rigorous physical flow equations for all major flow processes, but also permits more simplified descriptions.

MKE SHE has undergone limited verification (www.integratedhydro.com/reviews.html) to test its ability to simulate single component processes and some of their interactions. Though sophisticated and flexible, its ability to simulate evapotranspiration and stream-aquifer interactions could be improved. Verification emphasized that development and calibration requires a systematic approach and careful consideration of scaledependent integrated processes. Developing more complex, larger-scale integrated models requires specialized skills and a substantial investment in time.

The graphical interface is significantly improved in the 2003 version, offering a dynamic navigation tree, dynamic dialogs, and limited on-line documentation, and notably improved output animation capabilities. It seamlessly links with Arcview shape files and has well-organized spreadsheet-graphical functionality for ease in editing spatial and temporal input.

DHI offers the full version of MIKE SHE for about $\$ 10,000$, though simpler versions are less expensive and specialized add-on modules increase the price.

\section{MODFLOW}

MODFLOW-2005 is the most recent version of the U.S. Geological Survey (USGS) public domain MODFLOW software for simulating flow in saturated porous media in three dimensions with a finite difference grid.

A Geraghty and Miller survey of more than 5,000 groundwater modelers conducted in 1993 indicated MODFLOW was the most widely used groundwater model in the world. More than 23,000 copies of MODFLOW were downloaded from the main USGS web site from 1990 to 2000. Its popularity has continued, in part due to the modularity of the program and the resulting ability of USGS and others to add capabilities.

MODFLOW includes observation, sensitivity and parameter-estimation options with a convenient "Parameter" approach that facilitates model setup. A wide range of conditions can be represented using "Packages," including many recently-released new packages: The Hydrogeologic-Unit Flow (HUF) Package facilitates connection with hydrogeologic framework models such as EarthVision by populating the model grid with hydraulic parameters using defined hydrogeologic units. The Multi-Node Well (MNW) Package distributes flow in wells that intersect multiple model layers (for horizontal or angled wells, multiple nodes) and accounts for reduced pumpage caused by drawdown at the pumping well. The Geometric Multi-Grid (GMG) Package is efficient for solving large problems and is the first part of MODFLOW to be written in $\mathrm{C}$ rather than FORTRAN. The StreamFlow-Routing (SFR, replaces STR) Package routes surface water to streams and lakes, 
adjusting the river stage as stream discharge changes, such that flux to and from the groundwater system adjusts to the changing stage. The Subsidence and Aquifer-System Compaction (SUB3) Package simulates elastic compaction and expansion, and inelastic compaction of compressible fine-grained beds within the aquifer. Unsaturated Flow Packages are due out soon.

Some simple pre- and post-processing programs for MODFLOW are available from the USGS. These include GW_CHART, a program for evaluating model fit to observations and sensitivity analysis; and ModelViewer, a program to contour simulated heads. More powerful capabilities are available in a variety of interfaces that require purchase of commercial products. These can be found by searching for "MODFLOW interface" using a Web search engine. These programs facilitate construction of input files and assessment of results, but they do not support the latest MODFLOW capabilities, and errors in user understanding or bugs in the interfaces can yield misleading results.

Familiarity with the MODFLOW text files is important for trouble shooting, for using new MODFLOW features, and for dealing with unusual modeling situations. The new online guide of the USGS MODFLOW Web page provides a quick way to look up options and input formats. Download documentation, source code, and executables of MF2K and associated programs at no charge.

\section{MT3DMS}

MT3DMS is a public domain solute transport model for saturated porous media. In its current version it handles three-dimensional advective-dispersive transport of multiple chemical species and a range of simple chemical reactions. Moreover it serves also as the "engine" to compute advective-dispersive transport in other models that have more advanced reaction capabilities and for the variable density simulator SEAWAT. Notable features of MT3DMS that distingish it from many other solute transport models include the availability of several different numerical solution techniques for advective transport and the variety of boundary conditions and features that are needed to build realistic models. In particular the particle-tracking based solution schemes can produce results that are essentially free of numerical dispersion in the absence of excessive grid refinement a common problem among many other models.

Since its initial release as the single species simulator in 1990 MT3D, it has undoubtedly become the workhorse of computational contaminant hydrology. Of course, the most obvious reason for this is its full compatibilty with MODFLOW. Other important reasons for its popularity, among practitioners and researchers, are its robustness, which allows new users to quickly come up with accurate results, and its very good documentation which includes the availabilty of its source code. The source code of MT3DMS is written in Fortran using a MODFLOW-type easy to follow modular structure.

With MT3DMS, the transport of multiple species can be carried out simultaneously, whereby each species can be subject to sorption, either using linear, Freundlich or Langmuir isotherms, and/or first-order degradation reactions. This limits the reaction capabilities to cases where the reaction rates of each species can be assumed not to depend significantly on concentrations of other chemical species. That feature can be used, for example, to calibrate a (nonreactive) transport model (see Figures) by simultaneously carrying out simulations for several nonreactive species (or species that can in a particular case study be considered as being inert). MT3DMS capabilities also include a dual domain transport formulation that might be used for simulations of fractured or highly heterogeneous aquifers. MT3DMS, like MODFLOW, does not come with its own graphical user interface and thus its ease of use ultimately depends on the GUI selected for processing data input/output. However, as MT3DMS is supported by essentially all commonly used MODFLOW GUIs, users have a good choice among several products. MT3DMS can be downloaded for free from http://hydro.geo.ua.edu/mt3d/index.htm. The page contains also links to several GUI suppliers.

\section{ROCKWORKS}

RockWorks 2006, the latest version of subsurface visualization software from the Golden, Coloradobased RockWare, Inc., provides a large array of tools useful for site characterization in many earth science disciplines. For geologists, hydrogeologists, and geophysicists involved in water-resources investigations, the software package is particularly applicable for developing hydrostratigraphic models that facilitate construction of groundwater flow and transport models.

RockWorks 2006 provides centralized borehole database management in the Borehole Data Manager window. From this interface, borehole data, including lithology, stratigraphic contacts,geophysical data, geochemical measurements, fracture information, and groundwater levels can be used to create maps, cross sections, fence diagrams, single or multi-log plots, as well as three-dimensional surface and solid models. Other capabilities useful to water resources investigations are available in the RockWare Utilities window. This interface facilitates creation of contour maps of water levels and drawdowns, as well as Piper and Stiff diagrams. Utilities include statistical analyses andcontrol of display options. 
In addition to visualization of the subsurface for conceptual model development, RockWorks 2006 provides useful ways to create grids that can be used for modeling. For example, solids models created in RockWare can be exported as ASCII XYZ files, which can then be imported intovarious ground water modeling interfaces for defining model units and layers. Waterresource investigators will like the new Well Construction interface. This addition allows for detailed well construction information to be stored in adatabase format. With this data, RockWorks 2006 can be used to plot well construction diagrams alongside 2-D and 3-D strip-logs, allowing the user to identify the formation or lithology accessed by the screened intervals. Well features such as screen depth and length, casing length and construction materials can be included in the well construction diagram.

Several enhancements have been made to the 2004 version in order to generate RockWorks2006. One of the major enhancements is the Access database format now implemented for storage and management of borehole information. This new format increases the user's ability to query borehole information, and link data from various tables within the database. Checks on data integrity within the database have been improved (for example, checks on consistent layer elevations). The Access format in RockWorks does not require Microsoft Access to be installed for operation of the software. The option to import and manipulate data in a spreadsheet format is still available. The tool layout for creating borehole strip-logs has been improved and the edit capability in the 2006 version allows for editing of all graphics created in RockWorks. In addition to the export capabilities for grids, RockWorks 2006 now has more user-friendly options for exporting data to AutoCad and ArcGIS programs. RockWorks 2006 comes with an extensive help menu and several tutorials that help introduce the new user to the major features available with the software. The RockWare website (http://www.rockware.com/) provides further options for technical support. The software can be purchased online at www.rockware.com, or via telephone order at (800) 775-6745.

\section{References}

[1] Anderson, M.P. and Woessner, W.W., 1992. Applied Groundwater Modeling, Academic Press, Inc., San Diego, CA., 381 p.

[2] American Society for Testing and Materials, 1993. Standard Guide for Application of a Ground-Water Flow Model to a SiteSpecific Problem, ASTM Standard D 5447-93, West Conshohocken, PA, 6 p.

[3] American Society for Testing and Materials, 1995. Standard Guide for Subsurface Flow and Transport Modeling, ASTM Standard D 5880-95, West Conshohocken, PA, 6 p.

[4] Bear, J. and Verruijt, A., 1987. Modeling Groundwater Flow and Pollution, D. Reidel Publishing Company, 414 p.

[5] Franke, O.L., Bennett, G.D., Reilly, T.E., Laney, R.L., Buxton, H.T. and Sun, R.J., 1991. Concepts and Modeling in GroundWater Hydrology -- A Self-Paced Training Course, U.S. Geological Survey Open-File Report 90-707.

[6] Kashyap, Deepak, 1989. Mathematical Modelling for Groundwater Management - Status in India, Indo-French Seminar on Management of Water Resources, 22-24 September, 1989, Festival of France-1989, Jaipur, pp. IV-59 to IV-75.

[7] Kinzelbach, W., 1986, Groundwater Modeling: An Introduction with Sample Programs in BASIC, Elsevier, New York, 333 p.

[8] Kumar, C. P., 1992. Groundwater Modelling - In. Hydrological Developments in India Since Independence, A Contribution to Hydrological Sciences, National Institute of Hydrology, Roorkee, pp. 235-261.

[9] Kumar, C. P., 2001. Common Ground Water Modelling Errors and Remediation, Journal of Indian Water Resources Society, Volume 21, Number 4, October 2001, pp. 149-156.

[10] McDonald, M.G. and Harbaugh, A.W., 1988. A Modular Three-Dimensional Finite-Difference Ground-Water Flow Model, USGS TWRI Chapter 6-A1, $586 \mathrm{p}$.

[11] Pinder, G.F. and Bredehoeft, J.D., 1968. Application of the Digital Computer for Aquifer Evaluation, Water Resources Research, Vol. 4, pp. 1069-1093.

[12] Wang, H.F. and M.P. Anderson, M.P., 1982. Introduction to Groundwater Modeling, W.H. Freeman and Company, San Francisco, CA, 237 p.

[13] Website - Kumar Links to Hydrology Resources:

[14] http://www.angelfire.com/nh/cpkumar/hydrology.html

[15] Website - Scientific Software Group:

[16] http://www.scisoftware.com/

[17] Website - USGS Ground-Water Software:

[18] http://water.usgs.gov/nrp/gwsoftware/ 